\title{
POLÍTICAS EDUCACIONAIS PARA O ENSINO MÉDIO: IMPLICAÇÕES E PERSPECTIVAS PARA COM A GARANTIA DESSE DIREITO À EDUCAÇÃO
}

\author{
POLÍTICAS EDUCATIVAS PARA LA ESCUELA SECUNDARIA: \\ IMPLICACIONES Y PERSPECTIVAS PARA LA GARANTÍA DE ESTE DERECHO A LA \\ EDUCACIÓN
}

\author{
EDUCATIONAL POLICIES FOR HIGH SCHOOL: IMPLICATIONS AND \\ PERSPECTIVES FOR GUARANTEING THIS RIGHT TO EDUCATION
}

\author{
Danyella Jakelyne LUCAS GOMES ${ }^{1}$ \\ Maria da Conceição SILVA LIMA ${ }^{2}$ \\ Sidclay B. SOUZA ${ }^{3}$ \\ Margarete May BERKENBROCK-ROSITO ${ }^{4}$
}

RESUMO: O presente artigo se insere no âmbito das discussões que marcam os três primeiros anos de implementação do novo currículo do Ensino Médio no Brasil. Seguindo o paradigma qualitativo, realizamos uma pesquisa documental acerca dos instrumentos legais que amparam sua idealização, cujo objetivo foi compreender interfaces dessa reformulação na política educacional com outras alterações políticas, ligadas ao mercado e à regulação do Estado. Como resultado, a crítica ao modelo adotado, que mais parece uma readaptação do modelo tecnista da década de 70, enfraquecendo na atual conjuntura não apenas o direito das camadas populares à Educação Básica, como também à continuidade de estudos posteriores, além de abrir precedentes para a precarização do trabalho docente.

PALAVRAS-CHAVE: Reforma. Ensino médio. Estado regulador.

RESUMEN: Este artículo es parte de las discusiones que marcan los primeros tres años de implementación del nuevo plan de estudios de secundaria en Brasil. Siguiendo el paradigma cualitativo, realizamos una investigación documental sobre los instrumentos legales que apoyan su idealización, cuyo objetivo era comprender las interfaces de esta reformulación en la política educativa con otros cambios políticos, vinculados al mercado y la regulación del Estado. Como resultado, la crítica del modelo adoptado, que parece más una readaptación del modelo técnico de los años 70, debilita en la coyuntura actual no solo el derecho de los

\footnotetext{
${ }^{1}$ Universidade Federal de Pernambuco (UFPE), Recife - PE - Brasil. Professora substituta do Centro de Educação. Doutoranda em Educação (UFPE). ORCID: https://orcid.org/0000-0001-7043-9244. E-mail: danyellagomespe @hotmail

2 Universidade Federal de Pernambuco (UFPE), Recife - PE - Brasil. Professora Adjunta do Centro de Educação, Departamento de Administração Escolar e Planejamento Educacional. Doutorado em Educação (UFPE). ORCID: https://orcid.org/0000-0002-7358-5922. E-mail: mariacslimax @ hotmail.com

${ }^{3}$ Universidad Católica del Maule (UCM), Talca - Maule - Chile. Profesor Asistente do Departamento de Psicología, Facultad de Ciencias de la Salud. Pós-doutorando no Programa de Pós-graduação em Psicología (UFPE. ORCID: https://orcid.org/0000-0003-3727-3793. E-mail: sbezerra@ucm.cl

${ }^{4}$ Universidade da Cidade de São Paulo (UNICID), São Paulo - SP - Brasil. Professora do Programa de PósGraduação em Educação, Departamento de Educação. Doutorado em Educação (UNICAMP). ORCID: https://orcid.org/0000-0001-9010-1101. E-mail: margaretemay@uol.com.br
} 
estratos populares a la Educación Básica, sino también la continuidad de estudios adicionales, además de abrir precedentes para la precariedad del trabajo docente.

PALABRAS CLAVE: Reforma. Escuela secundaria. Estado regulador.

ABSTRACT: This article is part of the discussions regarding the first three years of implementation of the new high school curriculum in Brazil. Following the qualitative paradigm, we conducted a documentary research about the legal instruments that support its idealization, whose objective was to understand the interfaces of this reformulation in educational policy with other political changes, linked to the market and the regulation of the State. As a result, the criticism of the adopted model, which seems more like a re-adaptation of the technician model of the 70s, weakening in the current conjuncture not only the right of the popular strata to Basic Education, but also the continuity of further studies, besides opening precedents for the precariousness of teaching work.

KEYWORDS: Reform. Secondary school. Regulatory State.

\section{Introdução}

No ano de 2017, a última etapa da Educação Básica, o Ensino Médio, tomou destaque na esfera política e educacional. A proposta de alteração da Lei de Diretrizes e Bases da Educação Nacional - LDBEN no 9394/96, por parte do então governo de Michel Temer, teve por justificativa a necessidade de melhoria dos índices, tidos como insatisfatórios, tanto de conclusão quanto de qualidade, auferidos nas avaliações de larga escala, a exemplo do Exame Nacional do Ensino Médio - ENEM e do Programa Internacional de Avaliação de Estudantes - PISA. Tal cenário provocou e ainda provoca discussões entre educadores, políticos e o terceiro setor, tendo como principal gatilho, os rumos traçados para educação no país.

Os questionamentos englobam não apenas o conteúdo da proposta citada, como também, abarcam seu processo de sistematização, realizado segundo educadores, sem o devido debate com a sociedade e com aqueles que compõem a escola (AGUIAR, 2018). A própria introdução da proposta no meio educativo, no âmbito da Medida Provisória ${ }^{\circ}$ 746/2016, seria um dos agravantes, dando a ela um contorno mais impositivo, do que propriamente refletido, ponderado e exaurido.

Nesse processo esteve envolvida também uma discussão muito maior, relativa ao real objetivo nessa etapa, sendo sugerido o abandono de sua base propedêutica, e substituição por outra, tida pelos seus defensores como mais "alinhada" aos anseios da sociedade modernoindustrial e digital. 
Passados três anos da promulgação da Lei Federal $n^{\text {o }}$ 13.415/2017 que reformou o Ensino Médio, poucas alterações reais puderam ser sentidas, causando algumas incompreensões sobre os efeitos dessas mudanças. Considerando a necessidade de tornar o debate mais transparente, sobretudo, com o intuito de esclarecermos possíveis equívocos na compreensão dos seus efeitos, o presente capítulo traz uma discussão acerca dos principais elementos introduzidos pela referida Lei, atentando aos dispositivos de garantia do Direito a essa etapa da Educação Básica.

Com isso, nos propomos a discutir os elementos mais representativos da proposta que envolveu a alteração do Currículo Oficial, a introdução dos itinerários formativos, a ampliação da carga horária, a questão do notório saber, e as implicações para formação de professores.

Acreditamos que atrás do discurso envolvendo a urgência de mudanças imediatas e criação de mecanismos curriculares de atratividade entre os jovens, subjaz uma nuance muito mais política e social, inserida num contexto muito mais complexo de divisão do trabalho e da negativa de acesso ao ensino propedêudito às massas. E, isso nos faz ponderar acerca de antigas questões envolvendo o próprio histórico de estruturação e de consolidação do sistema educativo no país, sobretudo, no tocante ao acesso das camadas populares à Educação Básica.

Nesse sentido, não é a primeira vez que impasses envolvendo o objetivo dos três últimos anos da Educação Básica tomaram as atenções na sociedade brasileira. No caso em análise, a tônica de um currículo defasado pautou o discurso governamental e sustentou o caráter de urgência para a aprovação não apenas da Reforma do Ensino Médio, mas encabeçou direcionamentos dentro e fora do campo pedagógico. A medida é somada uma série de outras ações políticas, como a alteração nas leis trabalhistas, proposta de reforma da Previdência, Escola sem Partido, Homeschooling, que juntas, revelam uma nova postura em relação aos direitos e às garantias sociais, das quais a educação figura como uma das mais afetadas historicamente.

\section{Os pressupostos históricos do novo Ensino Médio}

Enquanto campo de disputas, o currículo converge em si encaminhamentos próprios de sua época e daqueles que legalmente têm o poder de conferi-lo. Nesse sentido, entendemos que sua formulação não ocorre no vazio ou com imparcialidade, uma vez que interage dentro de um núcleo social e econômico, determinados por forças, por vezes, condicionantes e palpáveis, que reinterpretam a realidade (PARO, 2011). 
Sendo assim, o entendimento da estrutura lançada por meio da Medida Provisória $\mathrm{n}^{\mathrm{o}}$ 746/2016 e, posteriormente, materializada na Lei Federal $n^{\circ} 13.415 / 2017$, transpassa uma série de outras compreensões, que não podem ser dissociadas no processo de análise do "novo" Ensino Médio. Elas não começam em 2017, mas possuem suas origens muito mais distantes, tendo relação direta com o lugar ocupado pelo Ensino Médio no interior das Políticas Educacionais, bem como, do seu financiamento, da representação social da etapa no contexto educativo brasileiro, e do campo de disputas dos agentes envolvidos.

De acordo com Azevedo (1997), os pressupostos reformistas estão na gênese do processo educativo no país e acompanham o movimento de funcionamento do projeto de sociedade que se deseja formar. Para Saviani (2001), dentro do próprio contexto de colonização e de cerceamento de incentivos à emancipação intelectual, podemos afirmar que as ações educativas sempre tiveram mais focadas no processo de construção individual e elitista, do que coletivo, sendo um eficiente divisor entre os ricos e os mais pobres.

As iniciativas pioneiras dos jesuítas e dos pombalinos revelam uma situação de total indiferença com a continuidade dos estudos, para além dos anos primários. De acordo com Vieira (2007), esse quadro pode ser nitidamente observado no âmbito das leis que ancoraram uma educação alinhada ao processo político e econômico no país, que, mesmo após a superação da condição de colônia, na Constituinte de 1824, já pavimentou o destino de secundarização da etapa, ao declarar a obrigatoriedade apenas da instrução primária.

Tal exemplo foi mantido após a proclamação da República, na Constituição de 1891, e nas tentativas de inúmeras Reformas Educacionais, que não delineavam a essência e o objetivo dos anos compreendidos entre o primário e o Superior, fazendo com que esse período ganhasse inúmeras interpretações e identidades, ora visando o preparatório para o Superior, ora visando a qualificação para entrada no mercado de trabalho.

O exemplo mais claro esteve presente na década de 1930. A efervescência dos movimentos sociais, com destaque para o Manifesto dos Pioneiros da Educação Nova oportunizou outros olhares. Conferindo à educação o status de direito compartilhado por todos, a Constituição de 1934 só estendia a garantia aos quatro primeiros anos do Primário. Além disso, a existência de testes de admissão ao ginásio freava qualquer perspectiva de acesso e, consequentemente, comprometia a continuidade de estudos em níveis mais elevados.

O pensamento operado nos anos seguintes ao surto industrial apregoava uma dualidade de ensino e de direcionamentos que, ao que parece, voltou à tona com a Lei $\mathrm{n}^{\circ}$ 13.415/2017. Às camadas populares, o ensino pré-vocacional, nomeadamente técnico, parecia como mais adequado. Foi assim que na década de 1940, o Sistema "S" (SESI, SESC, SENAI, 
SENAC) ganhou corpo, focando em uma parcela específica da sociedade, reforçando o entendimento excludente e de inclinações naturais das classes.

Diante disso, a principal analogia trazida por Moll (2017), Frigotto e Motta (2017), em relação à atual reforma, tem origens no movimento reformista da década de 1970 , e na reestruturação dos níveis de ensino com a Reforma do $1^{\circ}$ e do $2^{\circ}$ graus, no governo dos militares. O fim das provas de admissão ao ginásio não significou, necessariamente, a democratização do ingresso ou maiores investimentos. Tal contexto, alicerçado pelos acordos de cooperação entre o Ministério da Educação e Cultura e a USAID ${ }^{5}$, engessaram toda e qualquer possibilidade de mudança na etapa, marcada pelo Tecnicismo.

A compulsoriedade do ensino profissionalizante nas escolas esbarrou, sobretudo, na falta de elementos financeiros que a custeasse, gerando instabilidades e indefinições no cenário educacional do país. As instabilidades do cenário acarretaram em outro movimento de reforma, conhecido como "contrarreforma" de 1982 que, por meio da Lei Federal n 7044/1982, e encabeçado por representantes das instituições de ensino privadas, alterou os dispositivos acerca da obrigatoriedade do ensino profissionalizante, tornando-o facultativo.

$\mathrm{Na}$ década de 80, a ruptura aparente com a dualidade, tratada no artigo 208 da Constituição Federal de 1988, que colocava o até então $2^{\circ}$ grau como etapa final da Educação Básica, permitiu uma nova interpretação: a de que os três últimos anos conferiam um fechamento da base necessária para o prosseguimento em estudos ulteriores. Sendo assim, revestido de uma aparente valorização, o Ensino Médio apareceu como opcional, em suas nuances de propedêutica ou técnica, deixando ao estudante a incumbência democrática de suas escolhas.

O processo de abertura política e de redemocratização iniciado colocou no centro do debate mais uma vez o Ensino Médio, sobretudo, no que se refere às suas finalidades, que foram explicitadas no art. 35, da LDBEN no 9394/1996. A referida Lei, ao revogar a estrutura de $1^{\circ}$ e $2^{\circ}$ graus, reorganizou e ampliou a definição acerca do direito à educação. Nela estabeleceu-se como finalidade o aprofundamento e consolidação dos conhecimentos adquiridos no Ensino Fundamental, a preparação para o trabalho e cidadania, a formação ética e integral do educando e a compreensão dos fundamentos científico-tecnológicos do processo educativo (BRASIL, 1996).

Tais finalidades se constituem como o caminho a ser percorrido para a garantia do direito à educação e da formação plena. Conforme aponta Cury (2008), a Educação Básica na

\footnotetext{
5 Abreviatura para United States Agency for International Development, agência americana que influenciou na
} organização e condução de Políticas Públicas Educacionais, sobretudo, na ditadura militar. 
nova legislação adquiriu caráter ampliado, uma vez que passou a ser entendida a partir de três dimensões essenciais: conceito inovador, sobretudo, em função da negação histórica (seletiva e elitista) do direito à educação; direito que abrange um recorte universalista de reconhecimento do direito ao conhecimento pela ação sistemática da organização escolar; e como organização, pois atinge o pacto federativo e se constitui como pilar da cidadania por reunir as três etapas - Educação Infantil, Ensino Fundamental e Ensino Médio e suas modalidades.

Contudo, resta-nos salientar da fragilidade ainda referente ao Ensino Médio. Apenas o Ensino Fundamental era obrigatório e direito subjetivo, garantido, inclusive, a criação posterior de um fundo específico de natureza contábil subvinculando recursos da educação, por meio do Fundo de Manutenção e Desenvolvimento do Ensino Fundamental e de Valorização do Magistério - FUNDEF.

Apesar dos avanços, a lei por si só não garantiu a sua plena efetividade ao Ensino Médio. Embora presente legalmente, enquanto etapa da educação tida por básica ao cidadão, não foram direcionadas políticas específicas que viabilizassem sua estruturação. Essa foi uma realidade também verificada nas Políticas Públicas Educacionais na década de 1990, a exemplo do Plano Decenal de Educação, no qual o foco restou no incentivo ao aumento nos índices de alfabetização, incorporados no Ensino Fundamental.

As reformas educacionais precisam ser entendidas em função do próprio processo de reforma administrativa do Estado que, a partir da década de 1990, passou assumir um caráter gerencialista e que trouxe implicações diretas para as Políticas Sociais e, consequentemente, as Políticas Educacionais. Conforme apontam Peroni, Caetano e Lima (2017, p. 418), “a educação, como parte de um projeto de nação, é disputada por visões antagônicas, tanto no sentido da sua direção, quanto da sua execução".

O fim do FUNDEF, em 2007, acenou possíveis alterações no campo do financiamento. A Emenda Constitucional - EC 53/2006, e sua posterior regulamentação pela Lei 11.494/2007, criou o FUNDEB - Fundo de Manutenção e Desenvolvimento da Educação Básica. Esse dispositivo finalmente garantiu a ampliação dos investimentos e a destinação de recursos ao Ensino Médio de forma efetiva, garantindo recursos financeiros para o acesso e a permanência dos estudantes, inclusive, aos que não tiveram o acesso em idade própria, mediante uma séria de medidas.

Para Oliveira (2014), esse momento representou um marco social, em que as Políticas Educacionais se alinharam com Políticas Sociais, possibilitando que um contingente expressivo da população tivesse a possibilidade, não apenas de concluir a Educação Básica, 
como também continuar os seus estudos, impulsionados por programas de estímulo e custeio do Ensino Superior. ${ }^{6}$

Os relatórios educacionais do Instituto Anísio Teixeira-INEP revelam o salto nos índices de matrícula e de redução na distorção idade-ano. Contudo, no ano de 2015, após o golpe que afastou a então presidente Dilma Rousseff, novas interpretações começaram a ser definidas. Nelas, foi advogada a caducidade do processo que envolvia tanto o currículo quanto os objetivos do Ensino Médio. Essas ideias culminaram na atual Reforma, levando-nos de forma análoga a Ferreti (2018), Aguiar (2018), Aguiar e Dourado (2018), a nos questionar a quais interesses ela se conectava, e quais os impactos dela decorrente no tocante ao processo de direito e de garantia ao Ensino Médio e à sociedade como um todo.

\section{Uma crítica ao modelo}

Em pouco mais de duas décadas, a LDB de 1996 já passou por vários processos de alteração. Cronologicamente, apenas no período entre os anos 2000 e 2002 não foram identificadas alterações. Tais mudanças sugerem que as reformulações do texto legal ocorrem aos poucos, e, geralmente, seguem uma lógica contemporânea de readequação às demandas, na qual a educação tem passado a se reorganizar sob justificativas globais e mercadológicas.

As modificações envolveram, de maneira geral, questões relacionadas ao currículo, financiamento, planejamento, organização da Educação Básica, formação e valorização dos trabalhadores da educação. No Brasil, elas estiveram intimamente ligadas ao contexto político, social e econômico no qual foram implementadas, apresentando-se, por vezes, como avanços ou como retrocessos.

No que se refere ao Ensino Médio, especificamente, a necessidade de repensá-lo já havia sido empreendida, por meio de várias propostas de reforma que tramitavam no âmbito do poder legislativo. A mais expressiva, e que estava em fase bem avançada no processo amplo de debates com as diversas instâncias da sociedade, era o Projeto de Lei $n^{\circ}$ 6840/2013, de autoria do Deputado Federal Reginaldo Lopes.

Entretanto, a proposta foi intempestivamente barrada, após o golpe de 2016. Sob a justificativa de que a reforma demandava um caráter de urgência, criou-se um contexto de radicalização, que colocou o Ensino Médio, novamente, em um cenário de disputas de

${ }^{6}$ Exemplos: Programa do Governo Federal de Apoio a Planos de Reestruturação - PROUNI, Expansão das Universidades Federais Brasileiras - REUNI, Sistema de Seleção Unificada - SISU. 
projetos distintos, cuja ênfase recaía sobre os rumos e os conteúdos da educação brasileira (AGUIAR, 2018).

Vale ressaltar que as reformas educacionais nos quatro últimos anos no Brasil acompanharam o movimento de continuidade de Reforma do Estado, ratificando o caráter gerencialista, pautado nos princípios da eficácia e da eficiência. E, embora o MEC tenha promovido debates públicos e disponibilizado uma plataforma on-line de sugestões para subsidiar a construção da BNCC, Aguiar (2018) revela que tais iniciativas não exauriram toda sua complexidade, nem oportunizaram a devida análise acerca dos impactos dessa mudança não só para Educação, como também para a sociedade brasileira como um todo.

Nesse cenário, Fagnani (2017) relata que se contrapunham grupos de educadores, de políticos partidários da Reforma e de representantes de organizações privadas, representando empresários educacionais, formando um campo de disputas e de interesses antagônicos. Em suma, para os defensores da proposta, a urgência na reformulação da etapa se baseava em duas justificativas principais: a baixa qualidade do Ensino Médio e altos índices de abandono e de reprovação na etapa.

Tais justificativas reforçaram o caráter contraditório pelo qual a Reforma foi posta em discussão, a ponto de ser implementada por meio da Medida Provisória $n^{\circ} 746 / 2016$, e materializada, posteriormente, com a promulgação da Lei Federal $n^{\circ} 13.415 / 2017$, no governo de Michel Temer. A natureza sui generis da sua implementação, portanto, esvaziou o conteúdo do debate, sobretudo, em função da medida autocrática e injustificada, que ignorou discussões já iniciadas em outros projetos.

Um dos elementos marcantes da Reforma do Ensino Médio foi a política de fomento à implementação de escolas de Ensino Médio em Tempo Integral. $\mathrm{O}$ então ministro da Educação Mendonça Filho indicou uma ampliação da carga horária de forma gradativa de 800 horas/anuais para 1000 horas/anuais, nos primeiros 5 anos, até alcançar um total de 1400 horas/anuais. Entretanto, o documento não estabeleceu prazo para a ampliação total, o que certamente fragiliza sua efetivação dentro de um país que possui cenários educativos distintos.

Entendemos que a crítica ao currículo vigente foi o maior mote para configuração da BNCC de modo que, para a sua efetivação, a aprovação do documento de reformulação do Ensino Médio era condição indispensável. Em virtude isso, foi formulada uma nova abordagem curricular flexível, com inspiração no sistema americano de créditos, possibilitando ao estudante uma "escolha" mais alinhada a suas aptidões individuais. O conceito de construção de competências, criticado por muitos educadores, retornou como 
elemento fim da educação na etapa, na qual em cada ano, os estudantes estariam vinculados a uma série de conteúdos que devem ser apreendidos.

Assim, o currículo foi idealizado com uma base comum, que deverá preencher $60 \%$ da carga horária total do Ensino Médio, e uma base flexível correspondente aos outros $40 \%$ a ser complementado pelos chamados Itinerários Formativos, nas áreas específicas do conhecimento de Linguagens, Matemática, Ciências da Natureza e Ciências Humanas e Sociais ou, a opção pela formação Técnica Profissional, tendo a seguinte estrutura.

Tais inovações alteraram o artigo 36 da LDB/96. Devemos observar que a ação deixou ao encargo dos Sistemas de Ensino Estaduais, a opção de ofertar um ou mais itinerários, conforme suas capacidades. Entendemos que colocar no âmbito da escolha e não da obrigatoriedade desvia a finalidade inicial configuradora da proposta, que se traduzia numa identificação do estudante com a etapa, resultando num índice menor de evasão. Portanto, a materialização da escolha pessoal se esvai, criando um vácuo entre a proposta e os mecanismos políticos de garantia do direito a um ensino flexível.

Diante disso, visualizamos uma futura ampliação das desigualdades educacionais em suas dimensões de acesso, tratamento e conhecimento, conforme apontam Sampaio e Oliveira (2015). Ela ocorrerá em face da oferta e do acesso a esses itinerários, provocando divisões palpáveis entre o nível de educação entre estados, entre Sistemas e, sobretudo, entre escolas da mesma rede de ensino, em face das ofertas e da velocidade de implantação do Ensino Integral. E nisso, observamos um claro retorno ao dualismo pelo qual essa etapa já passou com a Reforma de 1971, anteriormente comentada, e que acreditávamos ter sido superada.

Ainda no tocante às alterações curriculares, salientamos a obrigatoriedade apenas das disciplinas de Língua Portuguesa e de Matemática nos três anos, o que indica ao final da Educação Básica, uma formação específica e não generalista. Além disso, o ensino de Língua Inglesa tornou-se obrigatório, acabando com a anterior flexibilidade da obrigatoriedade, podendo essa ser de outra Língua Moderna.

Conforme apontado por Freitas (2014), houve uma tendência de estreitamento curricular, com ênfase no ensino em função das disciplinas avaliadas nas avaliações externas, o que põe em evidência a priorização de uma formação específica, em detrimento da formação integral do educando, finalidade preconizada na Constituição Federal de 1988 e reafirmada na Lei de Diretrizes e Bases atual.

Entendemos também que a oferta do Ensino Profissionalizante da forma com que se apresenta, indica um retorno claro à Teoria do Capital Humano, cujo maior foco é a formação 
das massas para entrada no mercado de trabalho, sugerindo um tipo de especialização precoce, se considerar que a etapa compreende dos quinze aos dezessete anos.

Com isso, enxergamos uma "nova" divisão entre o ensino propedêutico e o técnico que, conforme Gariglio, Almeida Júnior e Oliveira (2017), representa uma tendência de retorno ao "ufanismo" da profissionalização no Ensino Médio. Como já ocorrido na década de 70, tal condição atinge os filhos das classes trabalhadoras, sobretudo, se considerarmos que a reforma traz rebatimentos para o acesso ao Ensino Superior, uma vez que o Exame Nacional do Ensino Médio - ENEM, deve adequar-se também à nova configuração.

Além do que, ainda sobre esse item, temos a polêmica que envolve os docentes com notório saber, que poderão atuar no Ensino Médio no itinerário formativo da Formação Técnica. Na compreensão de Aguiar (2018), essa menção pode abrir precedentes para que, na falta de professores licenciados, esses também possam vir a ocupar as vagas nos demais itinerários, sem a devida formação para atuação no magistério da Escola Básica. Isso significa romper com uma política de fortalecimento e de luta pelo reconhecimento das licenciaturas como requisito para atuação no âmbito da Educação Básica no país.

Essa alteração pode implicar uma flexibilização não apenas da formação inicial, como também põe em risco políticas públicas e conquistas importantes acerca do reconhecimento da profissionalidade, da carreira e da valorização docente. Do mesmo modo, afeta a construção dos saberes envolvidos no processo de ensino-aprendizagem, que possibilitam a organização do saber em todas as suas configurações e nuances. A práxis pedagógica é algo muito mais complexa, carecendo de reflexões processuais e de conhecimentos direcionados ao trabalho coletivo de educação do sujeito.

Diante do que foi apresentado, criticamos o modelo por compreendermos que na prática, a proposta de ampliação da jornada não configura de fato o favorecimento de uma escola de tempo integral. Além do que, questionamos as reais condições estruturais das escolas de Ensino Médio no país, bem como o volume de recursos financeiros para a implantação do funcionamento em tempo integral, sobretudo, entre os Estados da federação que ainda dependem de complementação orçamentária da União para cumprir suas obrigações no pacto constitucional. Essa preocupação também envolve o aumento no Custo AlunoQualidade-CAQ que deverá ser alterado, em virtude da ampliação dos insumos para que esse aluno permaneça mais tempo na escola.

Salientamos também o impacto para aqueles alunos que compõem comunidades populares. Na realidade brasileira, esses por motivos variados, são inseridos precocemente no mercado de trabalho informal, e, certamente, não poderão adequar-se ao novo contexto de 
estudo. Assim, acreditamos que a essa ampliação, ao contrário de integrar, pode segregar ainda mais a população em idade escolar, fazendo surgir um novo contingente de jovens entre 15 e 17 anos fora da escola.

\section{Desafios e perspectivas: algumas reflexões}

Uma vez realizadas as ponderações acerca do modelo implementado, colocamos quatro preocupações envolvendo desafios e perspectivas que possam garantir não apenas o acesso, como também a permanência desses jovens na escola. A primeira, sem dúvidas, recai sobre o financiamento da etapa. Uma vez que houve o aumento da carga horária e a opção pelo ensino integral, certamente, o impacto na política de fundos será um ponto a ser considerado, dado o prazo de vigência do Fundeb.

Até então, não observamos nenhuma movimentação no atual governo acerca de sua renovação, ou da implementação de um novo fundo que cubra as futuras despesas com a etapa. Isso se torna problemático, pois a ausência de previsão legal inviabilizará certamente o oferecimento de mais de um itinerário formativo por parte dos sistemas de ensino, ocasionando o alijamento do principal mote da campanha da Reforma.

Outro aspecto ainda em relação ao financiamento, diz respeito à atuação dos organismos internacionais e a injeção do capital privado para a implementação da reforma. Não podemos esquecer que a medida limitadora dos gastos públicos, que atingiu também a educação, tornou inviável o cumprimento da Meta 20 do PNE (2014-2024) que trata do financiamento da educacional.

A segunda consiste em por em funcionamento as finalidades do Ensino Médio, estabelecidas pela LDB atual e no Plano Nacional da Educação (2014-2024), em consonância com o novo ordenamento legal da Reforma. De acordo com Saviani (2008, p. 226), “quando, no entanto, se pensa numa lei específica para a educação, é porque se está visando à sua sistematização e não apenas à sua institucionalização". A trajetória de formulação das leis educacionais tem revelado que a legislação por si só, não garante sua plena efetividade, uma vez que ao ser introduzida na materialidade da escola, essa passa a ser ressignificada pelos agentes.

Ademais, o texto legal parece não levar em consideração as peculiaridades das escolas e sistemas de ensino no país, bem como a parcela da população que demanda do atendimento em curso noturno, seja por ser estudante trabalhador, ou mesmo, por não ter interesse pelo ensino em tempo integral. A esses sujeitos, o direito à educação necessita ser igualmente 
garantido, respeitando-se as suas diferenças, sob a pena de criação de um novo contingente de indivíduos, que terão seus direitos educacionais suplantados pela inadequação da realidade educacional à social.

Em terceiro, as marcas de descontinuidade das políticas educacionais presentes na história da educação que se articulam ao cenário político. Uma reforma dessa amplitude não poderia ser pensada dissociada do campo do planejamento das demais políticas, programas sociais e educacionais que poderiam contribuir para uma oferta equilibrada de tal etapa, bem como garantir a permanência com sucesso.

E, por fim, a quarta preocupação diz respeito à tradição de adotar modelos de reforma prescritos por organismos internacionais, ou implementados em outros países, com tradição e história educacional complemente diversos do Brasil, sem levar em consideração o contexto e as peculiaridades da educação nacional. É preciso ir bem mais fundo nas questões sociais que permeiam a educação brasileira. Fatores como gravidez na adolescência, envolvimento com drogas e a busca precoce por trabalho englobam aspectos, para além da escola, mas que possuem impacto decisivo nos resultados gerados por essa esfera (VOLPI, 2014).

Importar elementos de sistemas educativos de países de primeiro mundo, cujos jovens se distanciam da realidade na qual se insere a maioria dos estudantes de escolas públicas, nos inúmeros contextos brasileiros, é voltar a cometer erros pretéritos e homogeneizantes que já se mostraram falidos em seus resultados.

Ademais, a aprovação da Base Nacional Comum Curricular da Educação Infantil, do Ensino Fundamental e do Ensino Médio de forma fragmentada, diz muito da possibilidade de ruptura que a reforma pode implicar acerca do conceito de Educação Básica. O que indica uma maneira estática e não fluída de compreender e de pensar o processo educativo em suas etapas, de forma contínua.

Tal conceito, que levamos mais de 30 anos para consolidar por meio de lutas sociais, pelo direito à educação pública e gratuita para todos, pode estar sob forte ameaça de desmonte e esvaziamento de conteúdo, dada a falta de comprometimento que o atual governo insiste em deixar claro. Não há dúvidas sobre a importância de uma lei que proponha uma melhoria na qualidade da educação. Entretanto, há de se considerar a forma pela qual tais alterações são colocadas em prática.

Nesse sentido, nos aproximamos do pensamento de Gadotti (2009), de que a concepção de Educação Integral não diz respeito apenas à ampliação de carga horária. Antes, refere-se, principalmente, à educação de responsabilidade ampliada, para além da atuação da 
escola focalizada na instrução, configurando-se como possibilidade para formação integral dos estudantes, e o pleno desenvolvimento das diversas dimensões que compõe o ser.

\section{Considerações finais}

Ao estabelecermos o Novo Ensino Médio como pano de fundo para analisarmos a questão do direito à educação, trouxemos para o centro do debate os aspectos conjunturais que permearam a tramitação da Medida Provisória e sua conversão na Lei Federal $\mathrm{n}^{\circ}$ 13.415/2017. Debate esse que se estabelece não sem resistência da sociedade civil, mas que se encontra em um amplo campo de disputa de forças hegemônicas para atender aos ditames do mercado.

Embora a educação figure como bem e serviço público, de oferta facultativa à iniciativa privada, não podemos deixar de destacar que esta, além de direito subjetivo garantido, se apresenta também como dever do Estado, devendo esse atuar no sentido de oferecê-lo, de modo a reduzir as desigualdades históricas que marcam a educação no país. A formulação e implementação de políticas públicas que potencializem o acesso e a permanência com sucesso no processo de escolarização, sobretudo, no Ensino Médio, deve ser o caminho a ser percorrido para a efetividade do direito.

Entretanto, num contexto de instabilidades e incertezas em relação ao campo social como um todo, no qual há uma clara tendência de recuo da ação do Estado, é necessário que o debate acadêmico se fortaleça, e ultrapasse a barreira dos centros de pesquisa, de modo a tornar a discussão mais transparente, acerca dos efeitos que tais reformas trazem em seu bojo.

A emergência de uma nova racionalidade na qual o Estado ganha novos contornos, se distância da figura de provedor dos direitos sociais, e assume um caráter de agente regulador. Tal distanciamento traz implicações acerca garantia dos direitos sociais como saúde, segurança e educação, ao passo que, a lógica do individualismo e da autorresponsabilização dos sujeitos se instala dentro de uma aparente normalidade pela sociedade.

Nesse contexto, à educação se apresentam desafios que se fazem presentes desde os tempos mais remotos, abrangendo a manutenção das etapas básicas, a efetividade da legislação educacional, a descontinuidade das políticas educacionais e a tendência em "transplantar" ideias pedagógicas e curriculares, sem refletir sobre a materialidade da escola básica brasileira (SAVIANI, 2008). Esses desafios se ampliam quando comparamos com a etapa do Ensino Médio e somam-se ao de sua universalização. A proposição de um "novo" 
Ensino Médio, na verdade, nada mais é que um retorno às velhas práticas e estratégias de contenção de acesso de camadas populares aos níveis mais elevados de ensino.

\section{REFERENCIAS}

AGUIAR, Márcia Ângela. A. S. Vinte Anos da LDB: da Base Nacional Comum à Base Nacional Comum Curricular. In: BRZEZINSKI, Iria. (Org.). LDB vinte anos depois: projetos educacionais em disputa. 1ed. Cortez Editora, v. 1, p. 71-94, 2018.

\section{AGUIAR, Márcia Ângela. A. S.; DOURADO, Luiz F. (Orgs.) A BNCC na contramão do} PNE 2014-2024: avaliação e perspectivas. [Livro Eletrônico]. Recife: ANPAE, 2018.

AZEVEDO, Janete Lins de. A educação como política pública. Campinas: Autores Associados, 1997.

BRASIL. Emenda constitucional n. 53, de 19 de dezembro de 2006. Dá nova redação aos art. $7^{\circ}, 23,30,206,208,211$ e 212 da Constituição Federal e ao art. 60 do Ato das Disposições Constitucionais Transitórias. Diário Oficial da União, Brasília, DF, 20 dez. 2006. Disponível em: http://www.planalto.gov.br/ccivil_03/constituicao/Emendas/Emc/emc53.htm. Acesso em: 05 jan. 2019.

BRASIL. Emenda Constitucional $\mathbf{n}^{\mathbf{0}} \mathbf{5 9}$, de 11 de novembro de 2009. Acrescenta $\S 3^{\circ}$ ao art. 76 do Ato das Disposições Constitucionais Transitórias para reduzir, anualmente, a partir do exercício de 2009, o percentual da Desvinculação das Receitas da União incidente sobre os recursos destinados à manutenção e desenvolvimento do ensino de que trata o art. 212 da Constituição Federal, dá nova redação aos incisos I e VII do art. 208, de forma a prever a obrigatoriedade do ensino de quatro a dezessete anos e ampliar a abrangência dos programas suplementares para todas as etapas da educação básica, e dá nova redação ao $\S 4^{\circ}$ do art. 211 e ao $\S 3^{\circ}$ do art. 212 e ao caput do art. 214, com a inserção neste dispositivo de inciso VI.

Diário Oficial da União, Brasília, DF, 12 nov. 2009. Disponível em: http://www.planalto.gov.br/ccivil_03/constituicao/emendas/emc/emc59.htm. Acesso em: 05 jan. 2019.

BRASIL. Instituto Nacional de Estudos e Pesquisas Educacionais Anísio Teixeira. Relatório do $2^{\circ}$ Ciclo de Monitoramento das Metas do Plano Nacional de Educação. Brasília, DF: Inep, 2018.

BRASIL. Lei n. 4.024, de 20 de dezembro de 1961. Fixa as Diretrizes e Bases da Educação Nacional. Diário Oficial da União, Brasília, DF, 27 dez. 1961. Disponível em: http://www.planalto.gov.br/ccivil_03/leis/L4024.htm\#: :text=LEI\%20N\%C2\%BA\%204.024 \%2C\%20DE\%2020\%20DE\%20DEZEMBRO\%20DE\%201961.\&text=Fixa\%20as\%20Diretri zes $\% 20 \mathrm{e} \% 20$ Bases $\% 20$ da $\% 20$ Educa $\%$ C3\%A7\%C3\%A3o\%20Nacional.\&text=a)\%20a\%20c ompreens $\% \mathrm{C} 3 \% \mathrm{~A} 3 \mathrm{o} \% 20 \mathrm{dos} \% 20$ direitos, grupos $\% 20$ que $\% 20$ comp $\% \mathrm{C} 3 \% \mathrm{~B} 5 \mathrm{em} \% 20 \mathrm{a} \% 20 \mathrm{co}$ munidade $\% 3 \mathrm{~B} \&$ text $=\% \mathrm{C} 3 \% 80 \% 20$ fam $\% \mathrm{C} 3 \%$ ADlia $\% 20$ cabe $\% 20$ escolher $\% 20$ o, deve $\% 20 \mathrm{dar}$ $\% 20 \mathrm{a} \% 20$ seus\%20filhos. Acesso em: 05 jan. 2019. 
BRASIL. Lei n. 5.692, de 11 de agosto de 1971. Fixa Diretrizes e Bases para o ensino de $1^{\circ} \mathrm{e}$ $2^{\circ}$ graus, e dá outras providências. Diário Oficial da União, Brasília, DF, 12 ago. 1971.

Disponível em:

http://www.planalto.gov.br/ccivil_03/leis/15692.htm\#: :text=LEI\%20No\%205.692\%2C\%20

DE\%2011\%20DE\%20AGOSTO\%20DE\%201971.\&text=Fixa\%20Diretrizes\%20e\%20Bases $\% 20$ para,graus $\% 2 \mathrm{C} \% 20 \mathrm{e} \% 20 \mathrm{~d} \% \mathrm{C} 3 \% \mathrm{~A} 1 \% 20$ outras $\% 20$ provid $\% \mathrm{C} 3 \% \mathrm{AAncias} . \&$ text $=$ Art.\&t ext=1\%C2\%BA\%20Para\%20efeito\%20do\%20que,m\%C3\%A9dio\%2C\%20o\%20de\%20segu ndo\%20grau. Acesso em: 05 jan. 2019.

BRASIL. Lei Federal n. 11.494, de 20 de junho de 2007 - Regulamenta o Fundo de Manutenção e Desenvolvimento da Educação Básica e de Valorização dos Profissionais da Educação - Fundeb. Diário Oficial da União, Brasília, DF, 21 jun. 2007. Disponível em: http://www.planalto.gov.br/ccivil_03/_ato2007-

2010/2007/lei/111494.htm\#: :text=LEI\%20N\%C2\%BA\%2011.494\%2C\%20DE\%2020\%20D E\%20JUNHO\%20DE\%202007.\& text=Regulamenta\%20o\%20Fundo\%20de\%20Manuten\%C 3\%A7\%C3\%A3o,de\%20que\%20trata\%20o\%20art.Acesso em: 23 out. 2019.

BRASIL. Lei n. 7.044, de 18 de outubro de 1982. Altera dispositivos da Lei $\mathrm{n}^{\circ}$ 5.692, de 11 de agosto de 1971, referentes a profissionalização do ensino de $2^{\circ}$ grau. Diário Oficial da União, Brasília, DF, 19 out. 1982. Disponível em:

https://www2.camara.leg.br/legin/fed/lei/1980-1987/lei-7044-18-outubro-1982-357120norma-pl.html. Acesso em: 23 out. 2019.

CURY, Carlos Roberto Jamil. A educação básica como direito. Cadernos de Pesquisa, v. 38, n. 134, p. 293-303, maio/ago. 2008. Disponível em:

http://www.scielo.br/pdf/cp/v38n134/a0238134.pdf. Acesso em: 10 mar. 2019.

FAGNANI. Eduardo. O fim do breve ciclo da cidadania social no Brasil (1988-2015).

Texto para Discussão. Unicamp. IE, Campinas, n. 308, jun. 2017.

FERRETTI, João Celso. A reforma do Ensino Médio e sua questionável concepção de qualidade da educação. Estudos Avançados, [s. 1.], v. 32, n. 93, p. 25-42, 2018.

FREITAS, Luiz Carlos de. Os reformadores empresariais da educação e a disputa pelo controle do processo pedagógico da escola. Educação \& Sociedade, Campinas, v. 35, n. 129, p. 1085-1114, out./dez. 2014.

FRIGOTTO, Gaudêncio; MOTTA, Vania Cardoso da. Por que a urgência da Reforma do Ensino Médio? Medida Provisória No 746/2016 (Lei No 13.415/2017). Educação \& Sociedade (Impresso), v. 38, p. 355-372, 2017.

GADOTTI, Moacir. Educação Integral no Brasil: inovações em processo. São Paulo. Editora e Livraria Instituto Paulo Freire, 2009.

GARIGLIO, José Ângelo; ALMEIDA JÚNIOR, Ademir Soares; OLIVEIRA, Claudio Marcio. O "Novo" Ensino Médio: implicações ao processo de legitimação da Educação Física. Revista Motrivivência, Florianópolis, v. 29, n. 52, p. 53-70, set. 2017. Disponível em: https://periodicos.ufsc.br/index.php/motrivivencia/article/viewFile/2175-

8042.2017v29n52p53/35032. Acesso em: 26 de abr. 2019. Acesso em: 19 jun. 2019. 
GHIRALDELLI JUNIOR, Paulo. História da educação brasileira. São Paulo: Cortez, 2006.

MOLL, Jaqueline. Reformar para retardar: a lógica da mudança no EM. Revista Retratos da Escola, Brasília, v. 11, n. 20, p. 61-74, jan./jun. 2017. Disponível em:

http://retratosdaescola.emnuvens.com.br/rde/article/view/771. Acesso em: 16 abr. 2019.

OLIVEIRA, Dalila Andrade. A política educacional brasileira: entre a eficiência e a inclusão democrática. Educação e Filosofia, Uberlândia, v. 28, n. especial, p. 225-243, 2014.

PARO, Vitor Henrique. O currículo do ensino fundamental como tema de política pública: a cultura como conteúdo central. Ensaio: Avaliação e Políticas Públicas em Educação, Rio de Janeiro, v. 19, n. 72, p. 485-508, jul./set. 2011.

PERONI, Vera et al. Reformas educacionais de hoje: implicações para a democracia. Revista Retratos da Escola, Brasília, v. 11, n. 21, p. 415-432, jul./dez. 2017. Disponível em:

http://retratosdaescola.emnuvens.com.br/rde/article/view/793/pdf. Acesso em: 29 abr. 2019.

PINTO, José Marcelino Rozendo. O financiamento da educação na Constituição de 1988: 30 anos de mobilização social. Revista Educação e Sociedade, Campinas, v. 39, n. 145, p. 846869, out./dez. 2018. Disponível em: http://www.scielo.br/pdf/es/v39n145/1678-4626-eses0101-73302018203235.pdf. Acesso em: 26 abr. 2019.

ROMANELLI, Otaíza Oliveira. História da educação no Brasil. 10. ed. Petrópolis/RJ: Vozes, 1978.

SAMPAIO, Gabriela Thomazinho Clementino; OLIVEIRA, Romualdo Portela de. Dimensões da desigualdade educacional no Brasil. Revista brasileira de Estudos Pedagógicos, v. 31, n. 3, p. 511-530, set./dez. 2015. Disponível em: http://seer.ufrgs.br/index.php/rbpae/article/view/60121. Acesso em: 03 ago. 2019.

SAVIANI, Dermeval. Desafios da construção de um sistema nacional articulado de educação. Revista Trabalho, Educação e Saúde, v. 6, n. 2, p. 213-231, jul./out. 2008. Disponível em: http://www.scielo.br/pdf/tes/v6n2/02.pdf. Acesso em: 03 ago. 2018.

VIEIRA, Sofia L. A educação nas constituições brasileiras: texto e contexto. Revista brasileira de Estudos Pedagógicos, Brasília, v. 88, n. 219, p. 291-309, maio/ago. 2007.

VOLPI, M. 10 desafios do ensino médio no Brasil: para garantir o direito de aprender de adolescentes de 15 a 17 anos. Brasília: Unicef, 2014. 


\section{Como referenciar este artigo}

LUCAS GOMES, Danyella Jakelyne; SILVA LIMA, Maria da Conceição; SOUZA, Sidclay B.; BERKENBROCK-ROSITO, Margarete May. Políticas Educacionais para o Ensino Médio: implicações e perspectivas para com a garantia desse direito à educação. Revista on line de Política e Gestão Educacional, Araraquara, v. 24, n. 2, p. 614-630, maio/ago. 2020. e-ISSN: 1519-9029. DOI: https://doi.org/10.22633/rpge.v24i2.13744

Submetido em: 10/02/2020

Aprovado em: 30/03/2020

Publicado em: 09/04/2020 